\title{
Article \\ Reducing the Core Losses of Fe-Si-B Amorphous Alloy Ribbons by High Cooling Rate Planar Flow Casting
}

\author{
Deren $\mathrm{Li}^{1}{ }^{1} * \mathbb{( D}$, Wenjun Wang ${ }^{2}$, Tiancheng $\mathrm{Liu}^{3}{ }^{3}{\text { Lijun } \mathrm{Li}^{3}}^{3}$ and Zhichao $\mathrm{Lu}^{1}$ \\ 1 School of Electrical Engineering, Beijing Jiaotong University, Beijing 100044, China; luzhch@bjtu.edu.cn \\ 2 CITIC Metal Co., Ltd., Beijing 100004, China; wangwj3@citic.com \\ 3 Advanced Technology and Materials Co., Ltd., China Iron and Steel Research Institute Group, \\ Beijing 100086, China; liutiancheng@atmcn.com (T.L.); lilijun@atmcn.com (L.L.) \\ * Correspondence: derenli@bjtu.edu.cn; Tel.: +86-10-51684316
}

Citation: Li, D.; Wang, W.; Liu, T.; Li, L.; Lu, Z. Reducing the Core Losses of Fe-Si-B Amorphous Alloy Ribbons by High Cooling Rate Planar Flow Casting. Materials 2022, 15, 894

https://doi.org/10.3390/

ma15030894

Academic Editors: Hongbin Bei and Emil Babić

Received: 13 December 2021

Accepted: 17 January 2022

Published: 25 January 2022

Publisher's Note: MDPI stays neutral with regard to jurisdictional claims in published maps and institutional affiliations.

Copyright: (C) 2022 by the authors. Licensee MDPI, Basel, Switzerland. This article is an open access article distributed under the terms and conditions of the Creative Commons Attribution (CC BY) license (https:// creativecommons.org/licenses/by/ $4.0 /)$

\begin{abstract}
In the planar flow casting (PFC) process, the cooling rate significantly affects the structure and properties of a cast ribbon. The influence of the thermal conductivity of the cooling wheel substrate on cooling rate was simulated by a numerical method, and it is shown that a higher thermal conductivity of the cooling wheel substrate leads to a higher cooling rate in the PFC process. Two copper-beryllium (Cu-2Be) rings with thermal conductivities of $175.3 \mathrm{~W} / \mathrm{m} \cdot \mathrm{K}$ and $206.5 \mathrm{~W} / \mathrm{m} \cdot \mathrm{K}$ were manufactured and installed onto a wheel core as the substrate of the cooling wheel. The effects of cooling rate on the soft magnetic properties of Fe-Si-B amorphous ribbons were investigated by pragmatic ribbon casting. The results show that the increment in the thermal conductivity of the cooling wheel substrate from $175.3 \mathrm{~W} / \mathrm{m} \cdot \mathrm{K}$ to $206.5 \mathrm{~W} / \mathrm{m} \cdot \mathrm{K}$ lowered the coercive force of amorphous ribbon from $2.48 \mathrm{~A} / \mathrm{m}$ to $1.92 \mathrm{~A} / \mathrm{m}$ and reduced the core losses at $1.4 \mathrm{~T}$ and $50 \mathrm{~Hz}$ by up to $22.1 \%$.
\end{abstract}

Keywords: planar flow casting; amorphous alloy ribbon; cooling rate; coercive force; core losses

\section{Introduction}

Fe-based amorphous ribbons play an important role in high-efficiency energy conversion devices, and have been widely used in the fields of electric power, power electronics and renewable energy as distribution transformers [1-3], medium-frequency inductors [4], reactors [5], and motors [6,7], etc. Fe-based amorphous ribbon materials are characterized as energy-saving materials, due to the one-step energy-saving production process of planar flow casting (PFC) [8], and the novel properties arising from their unique microstructure as well as the thin ribbon gauge [9]. Therefore, minor improvements in core losses could lead to considerable energy savings [10].

The PFC is a complicated non-equilibrium solidification process, where heat and mass transfer, multiphase fluid flow and solidification occur concurrently. The PFC process parameters can be divided into configuration parameters and casting process parameters. The configuration parameters mainly include nozzle configuration parameters, such as the slot width of the nozzle, inclination angle of nozzle, parallelism of the nozzle to the axis of the cooling wheel, etc., and cooling wheel configuration parameters such as the cooling wheel dimensions, thickness of the cooling wheel substrate and thermal conductivity of cooling wheel substrate, etc. The casting process parameters mainly include the temperature of molten alloy, applied pressure of the molten alloy to the bottom of the nozzle, the nozzle-wheel distance, velocity of cooling wheel substrate, and temperature and flow rate of coolant in the cooling wheel. PFC processes have been the subject of numerous studies by a number of scientists and engineers, with the emphases mainly focused on puddle formation [11,12] and process stability [13,14], as well as the influences of processing parameters and processing conditions on materials structure [15,16], ribbon thickness $[17,18]$, and ribbon surface topography $[19,20]$. 
Fe-based amorphous ribbons exhibit low core losses due to their ultra-thin thickness of 20-30 microns, higher electrical resistivity of $100-130 \mu \Omega \cdot \mathrm{cm}$ and lack of magnetocrystalline anisotropy. The demands of a high efficiency and energy saving pose a challenge to further reduce the core losses of amorphous ribbons. To date, numerous studies have been conducted on materials development $[2,9,21]$, subsequent annealing and the structural design of magnetic cores [3,22] to further reduce the core losses of Fe-based amorphous materials, cores, and components. However, few reports are found on the influence of process parameters on core losses of Fe-based amorphous ribbon produced by the PFC process.

This work studies the influence of the thermal conductivity of cooling wheel substrates on the cooling rate of Fe-based amorphous ribbon and investigates the effects of cooling rate on the soft magnetic properties of Fe-Si-B amorphous ribbons.

\section{Materials and Methods}

\subsection{Calculation Methods and Parameters}

To analyze the influence of the thermal conductivity of the cooling wheel substrate on the cooling rate of molten alloy during the PFC process, the heat and mass transfer during the PFC process were simulated by ANSYS FLUENT software. Figure 1a shows the schematic geometry configurations with the corresponding coordinate system, where $\mathrm{P}_{\mathrm{app}}$ is an applied pressure to the surface of molten metallic alloy, the coordinate origin is at the center of the cooling wheel and $x=0.0 \mathrm{~m}$ is aligned with the center of the nozzle slot. A detailed description of the physical model, solution method and boundary conditions is presented elsewhere [23]. The main calculation parameters employed for this simulation are listed as follows: the applied pressure at the nozzle bottom is $45 \mathrm{kPa}$, the cooling wheel outer diameter is $300 \mathrm{~mm}$, the thickness of the Cu-2Be ring is $10 \mathrm{~mm}$, the linear velocity of cooling wheel substrate surface is $20 \mathrm{~m} / \mathrm{s}$, the nozzle slot width is $0.3 \mathrm{~mm}$, the nozzle wheel gap distance is $0.15 \mathrm{~mm}$, the temperature of the molten alloy is $1420{ }^{\circ} \mathrm{C}$, the initial temperature of the $\mathrm{Cu}$-2Be substrate and circumferential air is $32{ }^{\circ} \mathrm{C}$, and the glass formation temperature of the Fe-Si-B alloy is assumed to be $750{ }^{\circ} \mathrm{C}$ [12]. Figure $1 \mathrm{~b}$ shows the Fe-Si-B amorphous ribbons prepared by PFC, employing the above geometry configuration and calculation parameters.
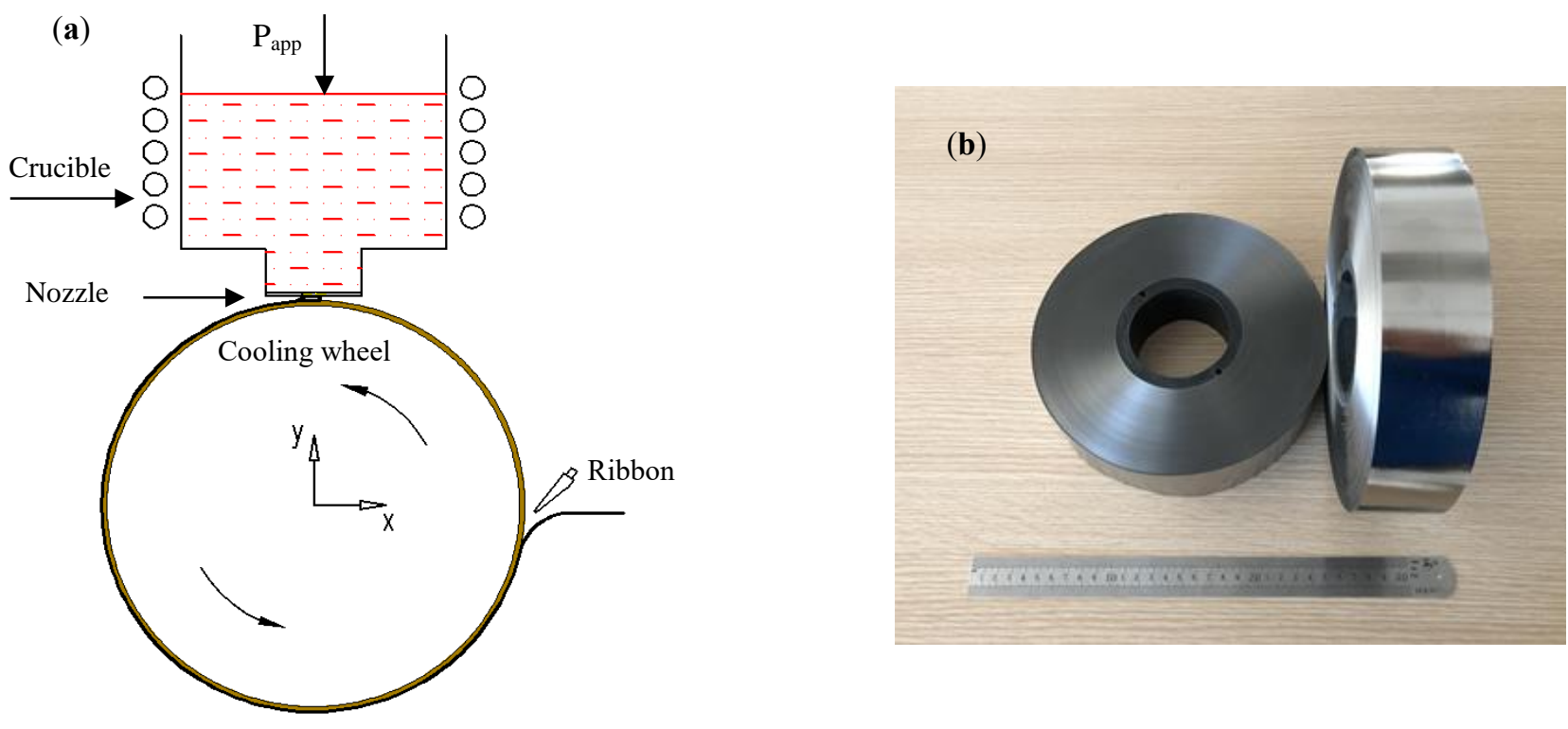

Figure 1. (a) The schematic geometry configurations with the corresponding coordinate system, where $\mathrm{P}_{\mathrm{app}}$ is an applied pressure to the surface of molten metallic alloy. The coordinate origin is at the center of the cooling wheel and $x=0.0 \mathrm{~m}$ is aligned with the center of nozzle slot [23]. (b) The as-cast Fe-Si-B amorphous ribbons. 


\subsection{Experimental Methods}

Two hot-rolled copper-beryllium (Cu-2Be) cylindrical rings were manufactured from the same wrought cylindrical ingot. The composition of the $\mathrm{Cu}-2 \mathrm{Be}$ rings is $\mathrm{Be}_{1.87} \mathrm{Co}_{0.26} \mathrm{Ni}_{0.01}$ $\mathrm{Fe}_{0.03} \mathrm{Al}_{0.02} \mathrm{Si}_{0.03} \mathrm{Cu}_{97.77}(\mathrm{wt} . \%)$. The hot-rolled rings were firstly solution annealed at $785^{\circ} \mathrm{C}$ with a soaking time of $3 \mathrm{~h}$ and then water quenched within $30 \mathrm{~s}$ in a water tank with water agitation. The aging treatments of the solution-annealed $\mathrm{Cu}-2 \mathrm{Be}$ rings were carried out at $335^{\circ} \mathrm{C}$ and $380^{\circ} \mathrm{C}$ with soaking times of $4 \mathrm{~h}$ and $6 \mathrm{~h}$ in a muffle furnace, respectively. The inner diameter, outer diameter and height of the machined cylindrical rings are $275 \mathrm{~mm}$, $305 \mathrm{~mm}$ and $300 \mathrm{~mm}$, respectively. The thermal conductivities of the two $\mathrm{Cu}-2 \mathrm{Be}$ rings are $175.3 \mathrm{~W} / \mathrm{m} \cdot \mathrm{K}$ and $206.5 \mathrm{~W} / \mathrm{m} \cdot \mathrm{K}$, respectively. A cooling wheel system is composed of a stainless steel wheel core and a cylindrical ring, where the wheel core has axially extended water channels formed about its outer peripheral surface, and the cylindrical ring was shrink-fitted onto the wheel core. The outer diameter of the $\mathrm{Cu}$-2Be ring on the cooling wheel was $300 \mathrm{~mm}$ after precision machining.

Alloy ribbons with a nominal composition of $\mathrm{Fe}_{80} \mathrm{Si}_{9} \mathrm{~B}_{11}$ (at. \%) were produced by using the $\mathrm{Cu}-2 \mathrm{Be}$ as the substrate of the cooling wheel. The ribbon width was $50 \pm 0.5 \mathrm{~mm}$ and the ribbon thickness was $25 \pm 0.5 \mu \mathrm{m}$.

XRD studies were carried out using a Bruker D8 Discover X-Ray diffractometer (Bruker in Berlin, Germany) with $\mathrm{CuK} \alpha$ radiation. The $2 \theta$ Bragg angle was varied from $20^{\circ}$ to $100^{\circ}$. The XRD measurements were carried out on the free surface of the as-cast ribbons.

The quasi-static hysteresis loops were measured using a MATS2010SD static magnetic property analyzer (LINK JOIN, Loudi, Hunan, China). The core losses and apparent power were measured using an IWATSU SY-8232 B-H analyzer (IWATSU, Tokyo, Japan). All the measured samples are toroidal cores, with an inner diameter of $30 \mathrm{~mm}$, outer diameter of $35 \mathrm{~mm}$, and height of $50 \mathrm{~mm}$, subjected to heat treatment (Advanced Technology and Materials Co., Ltd., Beijing, China) at $365^{\circ} \mathrm{C}$ for $60 \mathrm{~min}$ with an applied longitudinal field of $400 \mathrm{~A} / \mathrm{m}$.

\section{Results and Discussion}

\subsection{Estimation of Cooling Rate of Solidified Alloy during PFC Process}

To estimate the influence of the thermal conductivity of the cooling wheel substrate on the cooling rate of solidified alloy in the puddle region, the PFC process was simulated and thermal conductivities of $175.3 \mathrm{~W} / \mathrm{m} \cdot \mathrm{K}$ and $206.5 \mathrm{~W} / \mathrm{m} \cdot \mathrm{K}$ were used for the $\mathrm{Cu}-2 \mathrm{Be}$ rings as a substrate of the cooling wheel. It has been shown that the puddle reaches a quasi-steady state after the 60th revolution for a cooling wheel with a diameter of $300 \mathrm{~mm}$ and $\mathrm{Cu}-2 \mathrm{Be}$ thickness of $10 \mathrm{~mm}$ [23]. In this work, the PFC process with 130 revolutions was used to estimate the quasi-steady state. Figure 2 shows the simulation results of the upstream meniscus, downstream meniscus, and growth of liquid/solid interface at the 130th revolution for $\mathrm{Cu}$-2Be substrate with thermal conductivities of $175.3 \mathrm{~W} / \mathrm{m} \cdot \mathrm{K}$ and $206.5 \mathrm{~W} / \mathrm{m} \cdot \mathrm{K}$, respectively. In Figure 2, upstream meniscus and downstream meniscus are plotted by the line of the volume fraction of melt $=1$ (interface between air and liquid alloy), and the liquid/solid interface is plotted by the isothermal line of glass formation temperature $\mathrm{T}_{\mathrm{g}}=750{ }^{\circ} \mathrm{C} . \mathrm{P}_{1}$ and $\mathrm{P}_{2}$ are the Tri-junction of air, liquid alloy and solid nozzle wall, $\mathrm{P}_{3}$ and $\mathrm{P}_{4}$ are the Tri-junction of air, liquid alloy and solid ribbon, $\mathrm{T}$ is the ribbon thickness, $\mathrm{L}$ is the puddle length from $\mathrm{P}_{3}$ to $\mathrm{P}_{4}, \mathrm{U}$ is the linear velocity of the moving substrate surface of the cooling wheel, and $\mathrm{V}$ is the velocity of the solidification front. Figure 3 shows the calculation results of the interface temperature, between the solidified alloy and $\mathrm{Cu}-2 \mathrm{Be}$ substrate surface in the puddle region, for the $\mathrm{Cu}-2 \mathrm{Be}$ substrate with a different thermal conductivity at the 130th cycle. 


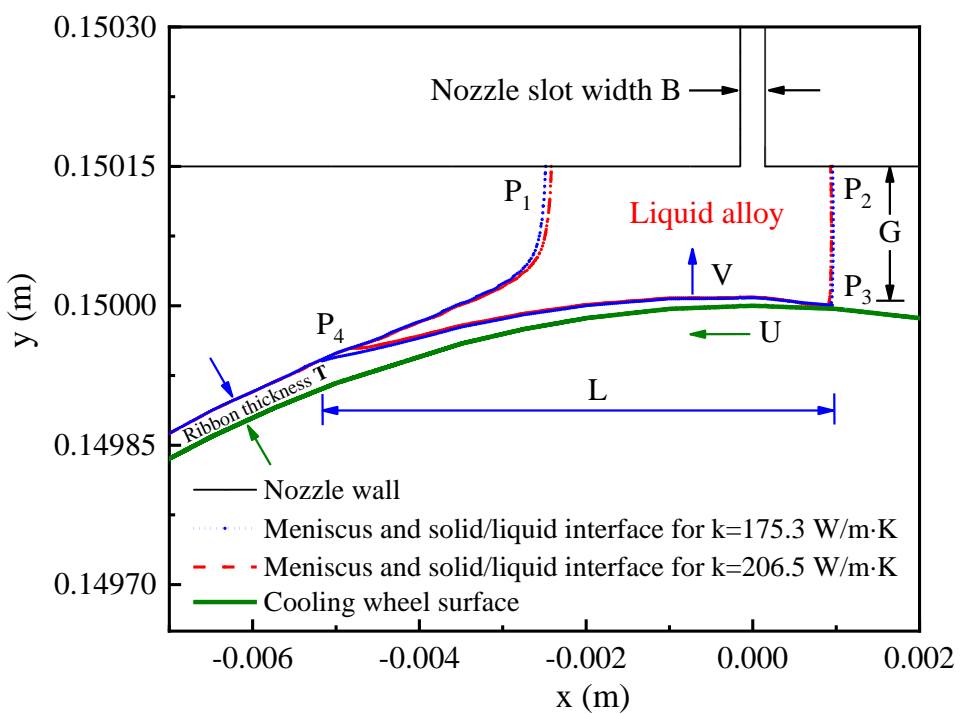

Figure 2. The simulation results of upstream meniscus, downstream meniscus, and growth of liquid/solid interface in quasi-static process for substrate thermal conductivities of $175.3 \mathrm{~W} / \mathrm{m} \cdot \mathrm{K}$ and $206.5 \mathrm{~W} / \mathrm{m} \cdot \mathrm{K}$, where $\mathrm{B}$ is the slot width of the nozzle, $\mathrm{G}$ is the nozzle wheel distance, $\mathrm{T}$ is ribbon thickness, $\mathrm{L}$ is the puddle length, $\mathrm{U}$ is the linear velocity of moving substrate surface of cooling wheel, and $\mathrm{V}$ is the velocity of solidification front.

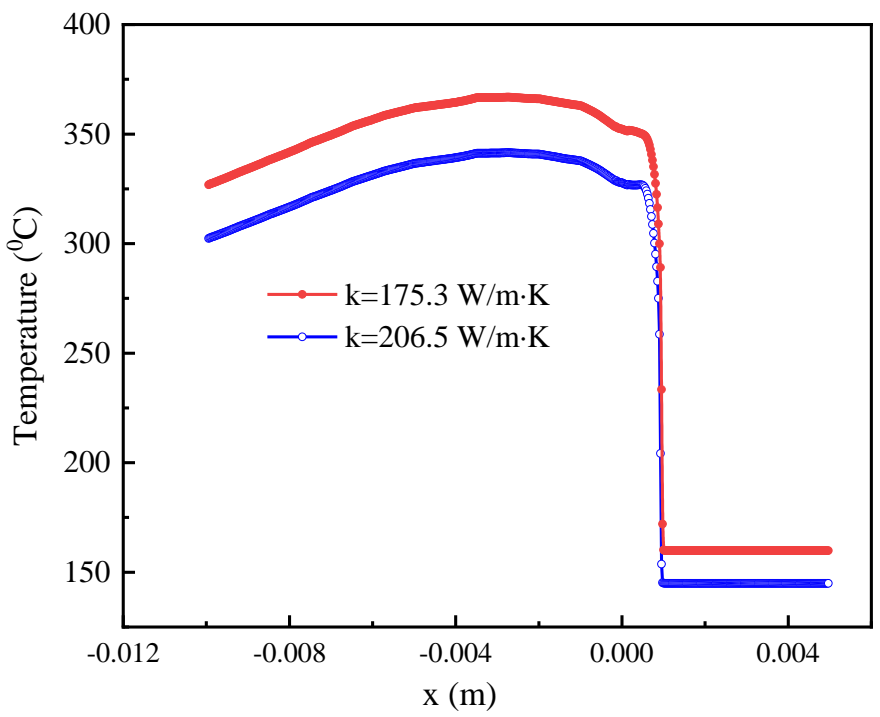

Figure 3. The calculation results of the interface temperature between the solidified alloy and $\mathrm{Cu}$ 2Be substrate surface in the puddle region for the $\mathrm{Cu}$-2Be substrate with thermal conductivities of $175.3 \mathrm{~W} / \mathrm{m} \cdot \mathrm{K}$ and $206.5 \mathrm{~W} / \mathrm{m} \cdot \mathrm{K}$ at the 130 th revolution. (Both viewed along Z-axis direction).

The growth of the liquid/solid interface is from $\mathrm{P}_{3}$ to $\mathrm{P}_{4}$ for this case. As shown in Figure 2, the solidification time is $\tau=\mathrm{L} / \mathrm{U}$, the cooling rate is estimated by $\eta=\left(\mathrm{T}_{\mathrm{g}}-\mathrm{T}_{\mathrm{s}}\right) / \tau$, where $T_{S}$ is the maximum interface temperature between the solidified alloy and $\mathrm{Cu}-2 \mathrm{Be}$ substrate surface in the puddle region. In order to calculate the corresponding cooling rate, data were extracted from the liquid/solid interface of the puddle and the interface temperature, between the solidified alloy and Cu-2Be substrate surface. Based on the extracted data listed in Table 1 , it can be calculated that the cooling rates are $1.2 \times 10^{6} \mathrm{~K} / \mathrm{s}$ and $1.44 \times 10^{6} \mathrm{~K} / \mathrm{s}$ for thermal conductivities of $\mathrm{k}=175.3 \mathrm{~W} / \mathrm{m} \cdot \mathrm{K}$ and $\mathrm{k}=206.5 \mathrm{~W} / \mathrm{m} \cdot \mathrm{K}$, respectively. The cooling rate increased by $14.3 \%$ due to the increment in substrate thermal conductivity. Therefore, the increase in thermal conductivity of cooling wheel substrate 
from $\mathrm{k}=175.3 \mathrm{~W} / \mathrm{m} \cdot \mathrm{K}$ to $\mathrm{k}=206.5 \mathrm{~W} / \mathrm{m} \cdot \mathrm{K}$ resulted in the corresponding increase in the cooling rates from $1.2 \times 10^{6} \mathrm{~K} / \mathrm{s}$ to $1.44 \times 10^{6} \mathrm{~K} / \mathrm{s}$, as shown by the calculation results.

Table 1. The coordinates of liquid/solid interface and the interface temperature between the solidified alloy and $\mathrm{Cu}-2 \mathrm{Be}$ substrate surface in the puddle region.

\begin{tabular}{ccccc}
\hline $\mathbf{K}(\mathbf{W} / \mathbf{m} \cdot \mathbf{K})$ & $\mathbf{P}_{\mathbf{3 x}}(\mathbf{m m})$ & $\mathbf{P}_{\mathbf{4 x}}(\mathbf{m m})$ & $\begin{array}{c}\mathbf{L}=\mathbf{P}_{\mathbf{3 x}}-\mathbf{P}_{\mathbf{4 x}} \\
(\mathbf{m m})\end{array}$ & $\mathbf{T}_{\mathbf{s}}\left({ }^{\circ} \mathbf{C}\right)$ \\
\hline 175.3 & 0.96 & -5.18 & 6.08 & 366.5 \\
206.5 & 0.92 & -4.76 & 5.68 & 341.2 \\
\hline
\end{tabular}

\subsection{Effect of Cooling Rate on Soft Magnetic Properties of Amorphous Ribbons}

To alter the cooling rate of solidified alloy in the puddle region during the PFC process, two $\mathrm{Cu}-2 \mathrm{Be}$ rings with thermal conductivities of $175.3 \mathrm{~W} / \mathrm{m} \cdot \mathrm{K}$ and $206.5 \mathrm{~W} / \mathrm{m} \cdot \mathrm{K}$ were installed in sequence onto the wheel core, and Fe-Si-B amorphous ribbons were produced by PFC. Figure 4 shows the XRD patterns of the as-cast Fe-Si-B ribbons produced by the cooling wheels, with substrate thermal conductivities of $175.3 \mathrm{~W} / \mathrm{m} \cdot \mathrm{K}$ and $206.5 \mathrm{~W} / \mathrm{m} \cdot \mathrm{K}$, respectively. It can be seen from the figure that both XRD patterns consist of only broad peaks without significant crystalline peaks, indicating that both the Fe-Si-B alloy ribbons are composed of an amorphous phase.

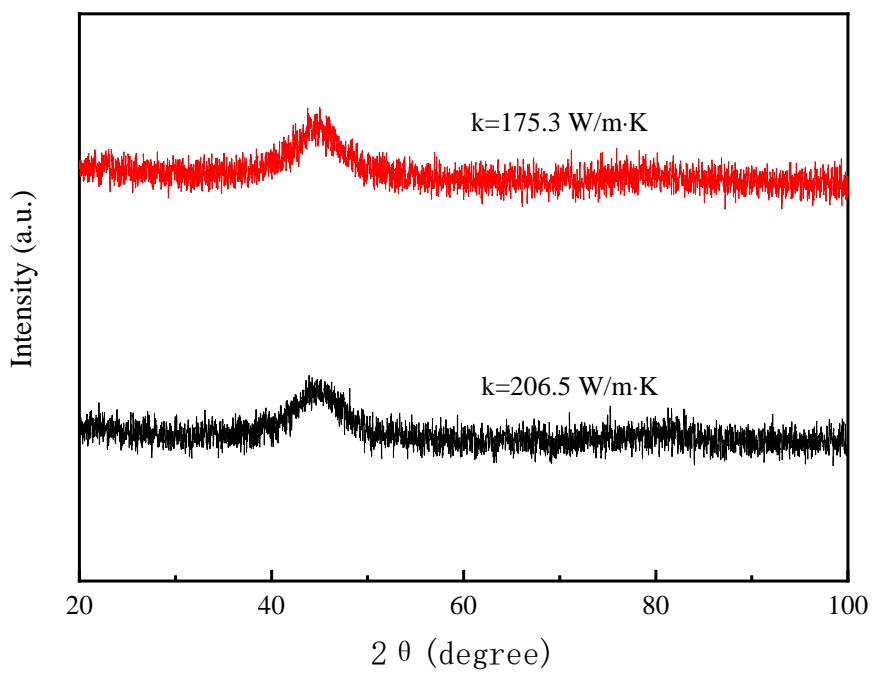

Figure 4. XRD patterns of the as-cast Fe-Si-B ribbons produced by cooling wheels with substrate thermal conductivities of $175.3 \mathrm{~W} / \mathrm{m} \cdot \mathrm{K}$ and $206.5 \mathrm{~W} / \mathrm{m} \cdot \mathrm{K}$.

Figure 5 shows the quasi-static hysteresis loops of Fe-Si-B ribbons produced by the cooling wheel with different substrate thermal conductivities and then annealed at $365{ }^{\circ} \mathrm{C}$ for $60 \mathrm{~min}$ with an applied longitudinal field of $400 \mathrm{~A} / \mathrm{m}$. Although the magnetic flux density at $80 \mathrm{~A} / \mathrm{m}$ has the same value of $\mathrm{B}_{80}=1.56 \mathrm{~T}$ for both ribbons, the coercive forces of the annealed ribbons are different, where the higher thermal conductivity value of $206.5 \mathrm{~W} / \mathrm{m} \cdot \mathrm{K}$ of the cooling wheel substrate corresponds to a lower coercive force value, $\mathrm{Hc}=1.92 \mathrm{~A} / \mathrm{m}$, and the lower thermal conductivity value $175.3 \mathrm{~W} / \mathrm{m} \cdot \mathrm{K}$ of the cooling wheel substrate corresponds to a higher coercive force value $\mathrm{H}_{\mathrm{c}}=2.48 \mathrm{~A} / \mathrm{m}$. Therefore, the increase in thermal conductivity of the cooling wheel leads to a decrease in the hysteresis loss of the annealed ribbon due to the reduction in coercive force. 


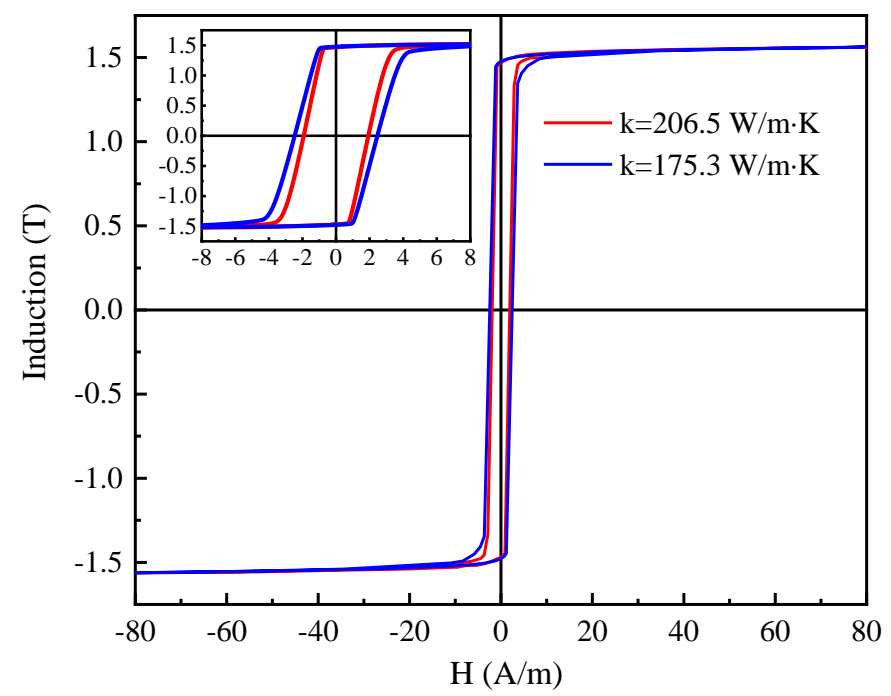

Figure 5. The quasi-static hysteresis loops of Fe-Si-B ribbons produced by cooling wheel with different substrate thermal conductivities and subjected to annealing at $365^{\circ} \mathrm{C}$ for $60 \mathrm{~min}$ with an applied longitudinal field of $400 \mathrm{~A} / \mathrm{m}$.

Figures 6 and 7 show the core losses and apparent power at $50 \mathrm{~Hz}$ as a function of flux density for Fe-Si-B ribbons produced by the cooling wheel with different substrate thermal conductivities and subjected to annealing at $365^{\circ} \mathrm{C}$ for $60 \mathrm{~min}$ with an applied longitudinal field of $400 \mathrm{~A} / \mathrm{m}$. The typical values of core losses and apparent power of annealed Fe-Si-B ribbons at $50 \mathrm{~Hz}$ and $1.4 \mathrm{~T}$ are summarized in Table 2. The increase in thermal conductivity of the cooling wheel substrate from $175.3 \mathrm{~W} / \mathrm{m} \cdot \mathrm{K}$ to $206.5 \mathrm{~W} / \mathrm{m} \cdot \mathrm{K}$ resulted in a decrease in core losses from $0.1708 \mathrm{~W} / \mathrm{kg}$ to $0.1331 \mathrm{~W} / \mathrm{kg}$. Meanwhile, the apparent power was reduced from $0.2374 \mathrm{VA} / \mathrm{kg}$ to $0.1762 \mathrm{VA} / \mathrm{kg}$. As the thermal conductivity increased from $175.3 \mathrm{~W} / \mathrm{m} \cdot \mathrm{K}$ to $206.5 \mathrm{~W} / \mathrm{m} \cdot \mathrm{K}$, the core losses and apparent power were reduced by up to $22.1 \%$ and $25.7 \%$ at $50 \mathrm{~Hz}$ and $1.4 \mathrm{~T}$, respectively. Thus, it can be concluded that an increase in thermal conductivity of the cooling wheel substrate leads to an increase in the cooling rate of solidified alloy in the PFC process, which results in the improvement of soft magnetic properties such as lower coercive force, lower core losses and lower apparent power.

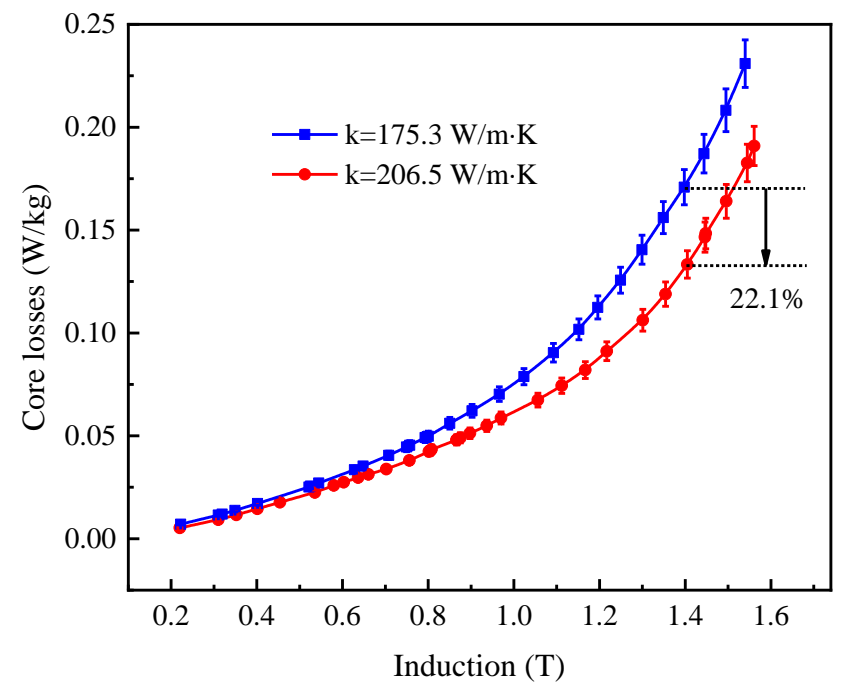

Figure 6. The core losses at $50 \mathrm{~Hz}$ as a function of flux density for Fe-Si-B ribbons produced by cooling wheel with different substrate thermal conductivities and subjected to annealing at $365^{\circ} \mathrm{C}$ for $60 \mathrm{~min}$ with an applied longitudinal field of $400 \mathrm{~A} / \mathrm{m}$. 


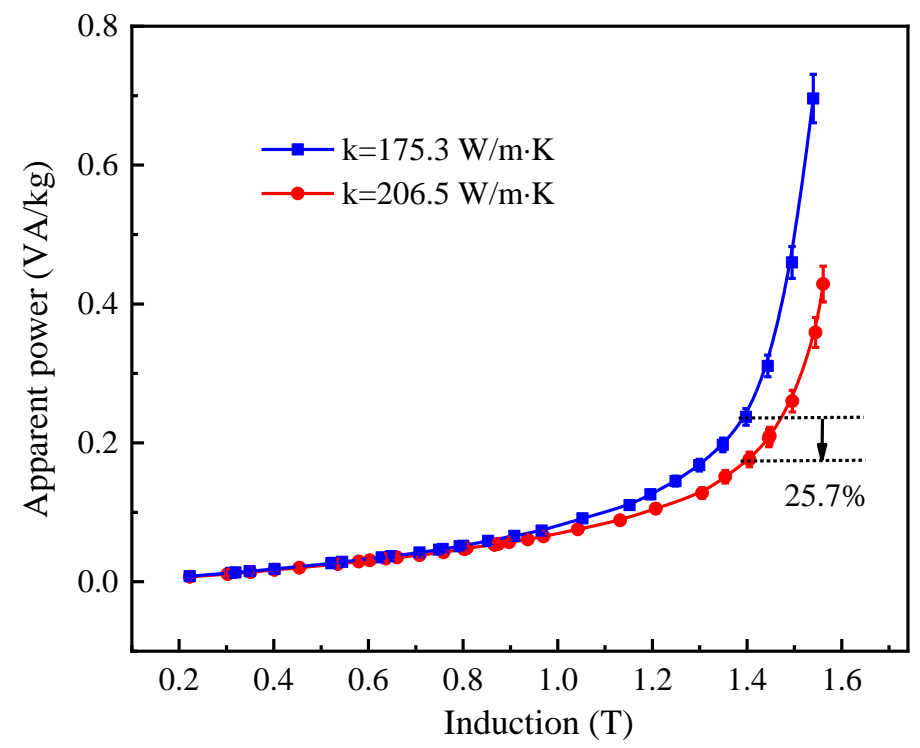

Figure 7. The apparent power at $50 \mathrm{~Hz}$ as a function of flux density for Fe-Si-B ribbons produced by cooling wheel with different substrate thermal conductivities and subjected to annealing at $365{ }^{\circ} \mathrm{C}$ for $60 \mathrm{~min}$ with an applied longitudinal field of $400 \mathrm{~A} / \mathrm{m}$.

Table 2. The cooling wheel condition and typical values of core losses and apparent power of Fe-Si-B ribbons subjected to annealing at $365^{\circ} \mathrm{C}$ for $60 \mathrm{~min}$ with an applied longitudinal field of $400 \mathrm{~A} / \mathrm{m}$.

\begin{tabular}{ccc}
\hline $\begin{array}{c}\text { Thermal Conductivity of } \\
\text { Cooling Wheel }(\mathrm{W} / \mathbf{m} \cdot \mathrm{K})\end{array}$ & $\begin{array}{c}\text { Core Losses at } \mathbf{5 0 ~ H z} \text { and 1.4 } \\
\mathbf{T}(\mathbf{W} / \mathbf{k g})\end{array}$ & $\begin{array}{c}\text { Apparent Power at 50 Hz } \\
\text { and 1.4 T (VA/kg) }\end{array}$ \\
\hline 206.5 & 0.1331 & 0.1762 \\
175.3 & 0.1708 & 0.2374 \\
\hline
\end{tabular}

\section{Conclusions}

The influence of the thermal conductivity of the cooling wheel substrate on the cooling rate in the PFC process was simulated by a numerical method, and the results show that the increase in the thermal conductivity of the cooling wheel substrate from $175.3 \mathrm{~W} / \mathrm{m} \cdot \mathrm{K}$ to $206.5 \mathrm{~W} / \mathrm{m} \cdot \mathrm{K}$ led to an increase in cooling rate from $1.2 \times 10^{6} \mathrm{~K} / \mathrm{s}$ to $1.44 \times 10^{6} \mathrm{~K} / \mathrm{s}$ during the PFC process. The effect of cooling rate on the soft magnetic properties of Fe-Si-B amorphous ribbons was investigated by practical ribbon casting, using cooling wheels with different thermal conductivities. It was revealed that the increase in the thermal conductivity of cooling wheel substrate from $175.3 \mathrm{~W} / \mathrm{m} \cdot \mathrm{K}$ to $206.5 \mathrm{~W} / \mathrm{m} \cdot \mathrm{K}$ in the PFC process resulted in a decrease in the coercive force of amorphous ribbon from $2.48 \mathrm{~A} / \mathrm{m}$ to $1.92 \mathrm{~A} / \mathrm{m}$, and the reduction in core losses and apparent power at $1.4 \mathrm{~T}$ and $50 \mathrm{~Hz}$ up to $22.1 \%$ and $25.7 \%$, respectively. This work provides an effective method of reducing the core losses of Fe-Si-B amorphous ribbons by means of increasing the cooling rate in the PFC process.

Author Contributions: Conceptualization, D.L. and Z.L.; methodology, D.L. and T.L.; software, D.L. and L.L.; validation, D.L. and T.L.; formal analysis, D.L., T.L. and L.L.; investigation, D.L. and L.L.; resources, W.W., T.L. and Z.L.; data curation, D.L.; writing-original draft preparation, D.L.; writing-review and editing, W.W. All authors have read and agreed to the published version of the manuscript.

Funding: No specific funding was received for conducting this study.

Institutional Review Board Statement: Not applicable.

Informed Consent Statement: Not applicable. 
Data Availability Statement: The datasets analyzed and/or generated during the current study are available from the corresponding author on reasonable request. The data presented in this study are available upon request from the corresponding author.

Conflicts of Interest: The authors declare no conflict of interest.

\section{References}

1. Azuma, D.; Hasegawa, R. Audible noise from amorphous metal and silicon steel-based transformer core. IEEE Trans. Magn. 2008, 44, 4104-4106. [CrossRef]

2. Takahashi, K.; Azuma, D.; Hasegawa, R. Acoustic and Soft Magnetic Properties in Amorphous Alloy-Based Distribution Transformer Cores. IEEE Trans. Magn. 2013, 49, 4001-4004. [CrossRef]

3. Azuma, D.; Ito, N.; Ohta, M. Recent progress in Fe-based amorphous and nanocrystalline soft magnetic materials. J. Magn. Magn. Mater. 2020, 501, 166373. [CrossRef]

4. Rylko, M.S.; Lyons, E.J.; Egan, M.G. Revised Magnetic Performance Factors and Experimental Comparison of High-Flux Materials for High-Current DC-DC Inductors. IEEE Trans. Power Electr. 2011, 26, 2112-2126. [CrossRef]

5. Kurita, N.; Onda, K.; Nakanoue, K.; Inagaki, K. Loss estimation method for three-Phase AC reactors of two types of structures using amorphous wound cores in 400-kVA UPS. IEEE Trans. Power Electr. 2014, 29, 3657-3668. [CrossRef]

6. Dems, M.; Komeza, K. Performance Characteristics of a High-Speed Energy-Saving Induction Motor with an Amorphous Stator Core. IEEE Trans. Ind. Electron. 2014, 61, 3046-3055. [CrossRef]

7. Kolano, R.; Kolano-Burian, A.; Krykowski, K. Amorphous soft magnetic core for the stator of the high-speed PMBLDC motor with half-open slots. IEEE Trans. Magn. 2016, 52, 2003005. [CrossRef]

8. Narasimhan, M.C. Continuous casting method for metallic strips. U.S. Patent 1979, 4, 142-571.

9. Hasegawa, R. Advances in amorphous and nanocrystalline materials. J. Magn. Magn. Mater. 2012, 324, 3555-3557. [CrossRef]

10. Gutfleisch, O.; Willard, M.A.; Brück, E.; Chen, C.H.; Sankar, S.G.; Liu, J.P. Magnetic Materials and Devices for the 21st Century: Stronger, Lighter, and More Energy Efficient. Adv. Mater. 2011, 23, 821-842. [CrossRef]

11. Chen, C.W.; Huang, W.S. A modified free surface treatment for the modelling of puddle formation in planar flow casting process. ISIJ Int. 1995, 35, 393-401. [CrossRef]

12. Liu, H.P.; Chen, W.Z.; Qiu, S.T.; Liu, G.D. Numerical simulation of initial development of fluid flow and heat transfer in planar flow casting process. Metall. Mater. Trans. B 2009, 40B, 411-429. [CrossRef]

13. Byrne, C.J.; Theisen, E.A.; Reed, B.L.; Steen, P.H. Capillary puddle vibration linked to casting-defect formation in planar-flow melt spinning. Metall. Mater. Trans. B 2006, 37, 445-456. [CrossRef]

14. Byrne, C.J.; Weinstein, S.J.; Steen, P.H. Capillary stability limits for liquid metal in melt spinning. Chem. Eng. Sci. 2006, 61, 8004-8009. [CrossRef]

15. Sowjanya, M.; Reddy, T.T. Cooling wheel features and amorphous ribbon formation during planar flow melt spinning process. $J$. Mater. Process. Technol. 2014, 214, 1861-1870. [CrossRef]

16. Životský, O.; Markov, D.; Hrabovská, K.; Buršík, J.; Jirásková, Y. Analysis of Magneto-Optical Hysteresis Loops of Amorphous and Surface-Crystalline Fe-Based Ribbons. Materials 2021, 14, 141. [CrossRef]

17. Anestiev, L.A. An analysis of the dependence of between the ribbon dimensions and the technological parameters for the planar flow casting method. Mat. Sci. Eng. A 1991, 131, 115-121. [CrossRef]

18. Li, D.R.; Zhuang, J.H.; Liu, T.C.; Lu, Z.C.; Zhou, S.X. The pressure loss and ribbon thickness prediction in gap controlled planar-flow casting process. J. Mater. Process. Technol. 2011, 211, 1764-1767. [CrossRef]

19. Cox, B.L.; Steen, P.H. ‘Herringbone' defect formation in planar-flow melt spinning. J. Mater. Process. Technol. 2013, $213,1743-1752$. [CrossRef]

20. Su, Y.G.; Chen, F.; Wu, C.Y.; Chang, M.H. Effect of surface roughness of chill wheel on ribbon formation in the planar flow casting process. J. Mater. Process. Technol. 2016, 229, 609-613. [CrossRef]

21. Dong, C.; Inoue, A.; Wang, X.H.; Kong, F.L.; Zanaeva, E.N.; Wang, F.; Bazlov, A.I.; Zhu, S.L.; Li, Q. Soft magnetic properties of $\mathrm{Fe}_{82-83} \mathrm{~B}_{14-15} \mathrm{Si}_{2} \mathrm{C}_{0.5-1}$ amorphous alloys with high saturation magnetization above 1.7 T. J. Non-Cryst. Solids 2018, 500, 173-180. [CrossRef]

22. Li, D.R.; Zhang, L.; Li, G.M.; Lu, Z.C.; Zhou, S.X. Reducing the core loss of amorphous cores for distribution transformers. Prog. Nat. Sci.-Mater. 2012, 22, 244-249. [CrossRef]

23. Li, D.R.; Lu, Z.C. The effects of aging on the cyclical thermal shock response of a copper-beryllium alloy as a substrate of cooling wheel in planar flow casting process. Mater. Res. Express 2020, 7, 116511. [CrossRef] 